\title{
INCLUSÃO DIGITAL EM ESCOLAS PÚBLICAS: TENDÊNCIAS PEDAGÓGICAS NAS SÉRIES INICIAIS
}

\author{
Lucivaldo Costa Moreira ${ }^{1}$
}

RESUMO: Analisando o crescimento da informatização dos serviços oferecidos à sociedade atual, cada vez mais se busca a necessidade da inclusão digital dos cidadãos nesse modo de vida. Ao acontecer o uso destes recursos tecnológicos, eles devem ser apropriados de meios onde a tecnologia da informação e comunicação (TIC) se direcione para fazer valer a inclusão dos indivíduos neste ciberespaço. Deste modo, a escola se apresenta como ambiente capaz de fazer imergir tais tecnologias a serviço de uma metodologia de ensino a favor da interação dos alunos nesta sociedade da informação anulando, assim, as diferenças sociais não pertinentes a este processo. Ao se utilizar diferentes mídias, que colaboram para a apropriação de um ambiente de comunicação, o computador e seus inúmeros recursos destacam-se como ferramenta de acesso apoiado por diferentes programas sociais do governo federal. Baseado nestes preceitos, o presente trabalho tem como objetivo analisar os principais desafios que a inclusão digital impõe sobre os anos iniciais do Ensino Fundamental na educação pública, do ponto de vista das barreiras e vantagens para a sua implementação. Trata-se de uma pesquisa em que foi utilizado o método de revisão bibliográfica, que é desenvolvida com base em um material formado, geralmente, por livros, sites oficiais, publicações periódicas e artigos científicos.

Palavras-chaves: Tecnologias da Informação e Comunicação. Inclusão Digital. Ensino Básico.

ABSTRACT: Analyzing the growth in the computerization of services offered to today's society, the need for digital inclusion of citizens in this way of life is increasingly sought. When these technological resources are used, they must be appropriated from means where information and communication technology (ICT) is directed to enforce the inclusion of individuals in this cyberspace. In this way, the school presents itself as an environment capable of immersing such technologies in the service of a teaching methodology in favor of the interaction of students in this information society, thus nullifying social differences not relevant to this process. When using different media, which collaborate for the appropriation of a communication environment, the computer and its countless resources stand out as an access tool supported by different social programs of the federal government. Based on these precepts, this paper aims to analyze the main challenges that digital inclusion imposes on the early years of elementary education in public education, from the point of view of the barriers and advantages for its implementation. It is research in which the bibliographic review method was used, which is developed based on material formed, generally, by books, official websites, periodical publications and scientific articles.

Keyword: Information and Communication Technologies. Digital inclusion. Basic education.

\footnotetext{
${ }^{\mathrm{I}}$ Mestre em Ciências da Educação pela Absoulute Christian University(2021), especializando-se em Psicologia Positiva e Coaching pela faculdade da região Serrana- FARESE, especialista em Matemática Financeira e Estatística pela Faculdade Única de Ipatinga(2020), especialista em Segurança de Rede de Computadores pela Faculdade Unyleya(2018), graduado em Análise e Desenvolvimento de Sistemas pelo Centro de Ensino Superior de Maringá (2016), graduado em Licenciatura em Matemática pela Universidade Norte do Paraná (2019). Estudou-se metade do Curso de Licenciatura em Química na UFPA (1998). Formou-se no Ensino Médio Técnico de Magistério (3 anos) e Contabilidade (3 anos). Por meio de processos seletivos estudou cursos profissionalizantes na área de Elétrica e Caldeiraria/soldagem financiados pela ALBRAS SA, onde estagiou por 30 dias em 1996 na área de elétrica. Ingressou em 1999, por meio de contrato, na SEDUC PA, como professor de química, física e matemática até $2008 \mathrm{em}$ Barcarena-Pa. Trabalhou no curso prévestibular da Prefeitura de Barcarena de 2000 a 2009 como professor de química. Por meio de concurso público ingressou na prefeitura de Barcarena em 2008 até 2010 como Assistente de administração, mas atuando significativamente como Técnico de Informática na Escola Aloysio da Costa Chaves. Em 2oro, em função do concurso público, compôs o quadro de funcionários do Banco do Estado do Pará em Barcarena, como Técnico Bancário e mas tarde (2014) exerceu a função de coordenação e retaguarda.
} 


\section{INTRODUÇÃO}

Nas últimas décadas, a sociedade vem passando por um processo de transformação em relação ao surgimento de novas tecnologias, os quais tem influenciado em todas as instâncias sociais, a inserção da informatização na sociedade provoca a necessidade urgente de inclusão digital das pessoas nessa nova dinâmica de vida, e uma dessas dinâmicas é a questão da educação e a grande necessidade do uso das tecnologias, que exige uma escola com capacidade de incorporar essas novas ferramentas em seu cotidiano escolar, demonstrando assim um grande desafio para o Brasil, na obtenção do sucesso na implantação de uma escola inclusiva e capaz de alcançar todos os cidadãos.

É a partir desse caminho que este tema foi escolhido em função de que a inclusão digital está em franco debate no país, e pelo presente ela impõe diversos desafios para a educação, por exemplo, como oferecer acesso à internet de qualidade para as regiões mais longínquas e remotas?

Como trabalhar reforços à distância se levarmos em consideração que os alunos nas cidades em sua maioria não possuem notebooks, impressores ou acesso à banda larga em sua casa? Como reestruturar as escolas públicas com equipamentos modernos em cada sala de aula com baixos investimentos dos governos? Esses e outros problemas são comuns entre alunos de norte a sul do nosso país. Ao passo também que é inegável que a inclusão digital possui grande potencial na educação sob o ponto de vista dos processos de ensino $e$ aprendizagem.

Dessa forma, considera-se de fundamental importância o tema por ser atual e envolver todos os segmentos da sociedade, tendo em vista que a escola é o local onde nossos estudantes da educação básica terão os alicerces básicos para a vida e para o ingresso na universidade. Espera-se, dessa forma, que a escola seja um espaço de constante construção do conhecimento, tendo como base ferramentas modernas como as novas tecnologias, com equidade no alcance à toda comunidade escolar.

Desta forma, o objetivo geral do trabalho será o de analisar os principais desafios que a inclusão digital impõe sobre os anos iniciais do Ensino Fundamental na educação pública, do ponto de vista de suas barreiras e vantagens para a sua implementação, e sendo uma pesquisa de caráter bibliográfico, tendo como público destinatário de leitura os 
educadores que são peça-chave nesse processo de inclusão digital escolar, haja vista que estão na linha de frente lidando diretamente com os alunos.

Este estudo está pautado em pensadores que defendem a teoria do Conectivismo (SIEMENS,2004 e BASTOS e BIAGIOTI 2014, p.03) aplicável a esta nova realidade que vivemos nos dias de hoje e buscam explicar como o comportamento humano se adapta às novas tecnologias na construção do saber. Pelo fato de ser um tema atual, está em constante debate por pesquisadores e é encontrado com bastante frequência na literatura, estudos como os de Prisote e Raiça (2017), Xabregas e Brasileiro (2019) e Scaranti(2017), Ribeiro (2019) são estudos recentes que abordam esse tema sob os mais diversos aspectos.

A principal colaboração que a pesquisa exibe é na apresentação dos vários desafios que a inclusão digital tem para o Ensino Fundamental, mostrando as vantagens e limitações existentes na sua implantação, contribuindo assim para o fomento da discussão, especialmente em nível local, estimulando reflexões aos docentes e gestores escolares que militam na educação pública. Para esse estudo propõem-se o seguinte problema: "Quais os principais desafios para a promoção da inclusão Digital nos anos iniciais do Ensino Fundamental da Escola Pública?”

\section{TECNOLOGIA E A MODERNIDADE}

De acordo com Araújo et.al (2017, p.or), o termo tecnologia nos remete à ideia de evolução, qualidade de vida e progresso e está intimamente ligada à história da humanidade, a qual percebe-se a existência de vestígios de tecnologia, ainda que rudimentares, empregadas no desenvolvimento das atividades mais cotidianas, mostrando a sua importância para todas as sociedades, "o avanço tecnológico se apresenta de forma progressiva influenciando a vida das pessoas, transformando o homem e sua cultura". Porém, vale à pena também observar, que a dependências dessas tecnologias podem gerar ambivalências, pois nem toda a sociedade possuem acesso igualitário a essas tecnologias.

Em tempos de modernidade, onde a tecnologia se apresenta como um dos pilares do desenvolvimento, faz-se importante a existência de reflexões sobre o acesso democrático dessas tecnologias, em especial quando tratamos do ambiente escolar, pois não se sabe ao certo se os estudantes têm acesso de forma igualitária às novas tecnologias de informação e 
comunicação, e se mais ainda conseguem se utilizar deles para a construção de saberes. A concepção de inclusão digital na educação passa por essa reflexão.

\begin{abstract}
Um grande desafio neste milênio é enfrentar essa herança social de injustiça, que exclui uma grande parte da população às condições mínimas de cidadania. Trazer para o presente todas as possibilidades do futuro, mas sem esquecer das mazelas que perduram do passado. A exclusão digital traz apenas mais uma faceta às outras exclusões já vividas e conhecidas por essa faixa da população; por isso há a preocupação em tratar a inclusão digital como uma facilitadora de outras inclusões, e não apenas focada no uso técnico das novas ferramentas (COSTA,2ori, p.rio).
\end{abstract}

Nesta direção, apresenta-se neste referencial um cenário e a contextualização da inclusão digital, que tem como pano de fundo as próprias tecnologias e as demandas sociais que surgem por elas que se relevam altamente excludente, quando se analisa pela péssima distribuição de renda, sendo capaz de gerar outras formas de inclusão, haja vista a alta dependência que a sociedade possui pelas tecnologias.

A modernidade tem causado mudanças rápidas e profundas no mundo que hoje é chamado de aldeia global, gerando interdependência em economia, saúde e educação, sendo assim, há uma necessidade de seus indivíduos estarem incluídos na era digital para que possam assim ter acesso aos novos serviços digitais que são ofertados por governos e organizações, inserindo nesse contexto o segmento da educação.

\title{
2.I Contexto histórico da inclusão digital
}

Para que se tenha uma melhor compreensão do contexto da inclusão digital é preciso antes realizar uma reflexão sobre como a sociedade altamente informatizada nesta era moderna, cuja característica remonta ao começo do século passado com o surgimento do computador, muito em evidência por exemplo nos anos 40, na Segunda Guerra Mundial e logo em seguida, com a invenção dos microcomputadores nos Estados Unidos nos anos 6o, onde a sociedade americana começa a ter o computador como sua principal ferramenta de trabalho e de atividades do cotidiano(ARAUJO, et al,2017).

Nos anos 70 o computador ocupa espaço nas instituições educacionais americanas, ganhando alta popularidade. Nos anos 80 a internet ganha dimensões reais, e nos anos 9o, ela se dissemina pelo mundo inteiro chegando inclusive no Brasil (ARAUJO et al,2017).

Levando-se em consideração a rápida disseminação das tecnologias pelo mundo, (Arretche, 2019 p.58) analisa que "se o mundo digital abriu oportunidades exponenciais de 
participação econômica e política, existem evidências de que oportunidades não sejam distribuídas igualitariamente", analisando sob este ponto de vista, na era do computador, percebe-se que constitui-se num espaço desigual com os mais diversos sistemas de governo, tendo sociedade ricas e desenvolvidas, porém também, aquelas com altos índices de pobreza, fazendo com que o cidadão apresente graves formas de exclusão social, onde lhes são negados acesso água potável, saneamento básico, saúde, como também a dificuldade de acesso à tecnologias, daí a emergência da inclusão digital”.

A inclusão digital deve ser pensada como uma questão de direito à ação política e ser objeto de ações governamentais, nas quais a inserção de novos instrumentos nessa área amplia os quatro capitais básicos para o indivíduo: social, cultural, intelectual e técnico (CERQUINHO et al, 2015, p.o2)

De acordo com Dias (2011, p.o8) para se compreender o que é inclusão digital, devese pensar em trabalhar inicialmente o conceito oposto, o da exclusão, introduzido na Sociedade da Informação para denunciar os processos que impendem a ampla maioria da população de ter acesso à comunicação mediada por computador, ou seja, de se utilizar das redes informacionais. Esses processos determinam a necessidade de promover uma inclusão digital para essas pessoas que estão sendo privadas deste direito básico.

\subsection{Inclusão digital: conceitos e caracteríticas}

Sendo assim, Dias (20II), tem a percepção de que a exclusão digital como a falta de acesso do cidadão às tecnologias de informação e comunicação, tão necessárias em nossos tempos, entendendo que essa exclusão não representa um processo natural, pois passa indubitavelmente por formulação de políticas públicas:

A negação do acesso é o núcleo da maior exclusão, aquele que impede que o cidadão chegue até um computador conectado à rede, do modo que quiser. Por não se tratar de um processo natural, pois não representa uma opção individual, o termo exclusão digital tem ainda, e infelizmente por um longo tempo, um enorme valor em seu uso. Ele identifica o fenômeno do bloqueio econômico e de infraestrutura que nega os segmentos mais pobres da sociedade a terem acesso as redes informacionais. Ele define um processo de exclusão que não permite que cidadãos tenham o mais básico contato com as redes digitais (SILVEIRA,2008 apud DIAS,2011, p.71).

Segundo Costa, (20II, P.ı1o) "entende-se por inclusão digital como uma forma de apoio aos cidadãos na perspectiva de inserção na sociedade moderna e contemporânea, buscando de maneira preferencial as populações que possuem baixos índices socioeconômicos”, o que acarreta na inclusão daquelas pessoas que tem menores chances 
de se apropriarem dos benefícios advindos das tecnologias. Esta questão se agrava ainda mais quando se observa que a exclusão digital não exclui apenas indivíduos da base socioeconômica de um país, mas também diversos outros segmentos como as pessoas portadoras de necessidades especiais, outros fatores ligados também à raça, gênero, idade e renda influenciam e colaboram diretamente para esse processo de exclusão, podendo ser nomeado de exclusão social.

Bonila e Preto (2016) classificam a inclusão em dois grandes grupos especiais: a espontânea e a induzida. A espontânea é definida pelos autores como aquela em que o cidadão é inserido na sociedade da informação, sendo o seu contato com as tecnologias acontecem de forma cotidiana e rotineira.

Já a inclusão induzida apresenta-se como um trabalho com o olhar das políticas públicas tendo como objetivo principal contemplar a população de fato excluída dos benefícios da sociedade da informação.

\subsection{O contexto pedagógico da inclusão digital}

Para Silva(2018), a educação absorve impactos diretos com a difusão das

Tecnologias da Informação e Comunicação (TICs), tendo em vista que, elas causam transformações de ordem paradigmática e estão impulsionando as pessoas a aceitarem a ideia de que as tecnologias possam oferecer meios eficazes de aprendizagem sem fronteiras e sem pré-requisitos, inclusive passando por processos bruscos de mudanças a partir da curta migração das TICS com as Tecnologias Digitais de informação e Comunicação (TDICs), sendo esta última, atrelada aos novos meios informatizados como Smatphones, aplicativos web 2.0, redes sociais, etc.

As novas TICs também estão presentes na rede pública de ensino básico do país, impactando o processo de ensino aprendizagem e gerando uma necessidade de reformulação e ressignificação do espaço escolar. Esse tema vem ganhando força e está no centro da discussão entre pesquisadores, educadores, professores e gestores, que discutem o uso das TICs na educação e a mudança que isso poderá causar no processo de ensino aprendizagem no país. Isso impacta sobremaneira o espaço educativo, implicando novas ideias de como repassar o conhecimento e o surgimento de novos conceitos de ensino e de aprendizagem, exigindo o repensar do currículo, da função da escola, do papel docente e discente (SILVA,2018, P.65)

Silva (2018, p.67) escreve ainda que "existe a ideia de que a educação deveria migrar das formas ditas tradicionais, que se utilizam de ferramentas como quadro, giz, a voz e um modelo escola que privilegia a lógica da instrução e apenas da transmissão de informação" 
em prol de um modelo denominado como "novo educacional" cuja base se fundamenta na construção colaborativa dos saberes tendo como eixo fundamental as TICs. Para que isso ocorra, apresenta-se neste trabalho a teoria do conectivismo que pode justificar esse processo de mediação do conhecimento com o uso das TICs ao mesmo tempo colaborando para inclusão digital e social no âmbito escolar.

A teoria do Conectivismo tem como um dos seus percussores o professor canadense George Siemens, que é um teórico dos processos de ensino e aprendizagem da era digital, esta abordagem se apresenta como uma modernização aos processos tradicionais e conservadores e da aprendizagem como Behaviorismo, Cognitivismo e Construtivismo justificados por Siemens como sendo teorias que "foram desenvolvidas num tempo em que a aprendizagem não sofria os impactos das tecnologias" e que, é notório como nos últimos 30 anos as tecnologias ocuparam espaço, modificando a forma de vida das pessoas, devendo os processos de ensino-aprendizagem refletir o momento atual que se vive.

A teoria do Conectivismo preconiza então "a inclusão das tecnologias e da realização de conexões como atividades na aprendizagem, fazendo com que as teorias da aprendizagem migrem para uma visão de um saber digital” (SIEMENS,2004, p.04).

A partir deste ponto de vista, não se deve mais de forma individual experimentar a aprendizagem que necessitamos sobre o mundo, sendo essa competência alcançada através de conexões entre as mais diversas fontes de informações que estão ao nosso dispor, e a partir daí, criar conceitos e padrões que vão gerar informações que serão absorvidas pelo indivíduo.

Nessas reflexões finais deste embasamento teórico faz-se alguns questionamentos como "sendo o Conectivismo uma teoria moderna que justifica o uso de tecnologias nos processos de ensino e aprendizagem como um elemento que agrega o conhecimento, de modo colaborativo e em rede, qual a sua importância para a inclusão digital dos alunos? Essa pergunta pode ser respondida com uma frase marcante do Siemens "a capacidade de aprender o que precisamos para amanhã é mais importante daquilo que conhecemos hoje”. Ou seja, ter acesso às informações, sabendo operar com as ferramentas digitais disponíveis, é muito importante para o conhecimento do indivíduo, para que isso aconteça, é necessário que as pessoas estejam ambientadas com o uso das TDICs, ou seja, é urgente a 
implementação de políticas públicas de inclusão digital nas escolas, para que os alunos possam se sustentar num pilar de aprendizagem que tem como base as novas tecnologias.

\subsection{Base nacional curricular e a inclusão digital}

A Base Nacional Curricular - BNCC é um documento de caráter normativo que norteia e define uma relação de aprendizagem básica que os alunos devem desenvolver segundo avançam em suas respectivas etapas e modalidades de ensino dentro da Educação Básica, cujo objetivo principal é o de alavancar a qualidade da educação no Brasil, por intermédio do estabelecimento de parâmetros mínimos de aprendizagem a que todos os estudantes do país possam usufruir (BRASIL,20I8 a).

É de conhecimento universal, que as TDICs, vem cada mais influenciados a forma de trabalhar de todos os atores envolvidos na área de educação, impactando a forma de trabalhar, comunicar e aprender, sendo ferramentas facilitadoras no processo de ensinoaprendizagem, dando suporte aos docentes no desenvolvimento de metodologias ativas, aproximando a construção do conhecimento com a realidade dos alunos (BRASIL,20I8a).

Percebe-se o estreito comprometimento entre a BNCC e o uso das tecnologias digitais aplicadas de forma transversal em todas as áreas do conhecimento com ampla citação em competências e habilidades, incorporando assim a sua exploração como ferramenta capaz de inserir o estudando numa prática social inclusiva.

\subsection{Legislação da inclusão digital}

O avanço tecnológico e o processo de inclusão digital desenvolvido pelo Brasil conforme visto no item anterior, amplia o debate se aproximando de vários segmentos governamentais, dentre eles a educação, cujo papel das tecnologias são de grande importância por serem ferramentas que contribuem com os processos de ensino e aprendizagem no cotidiano escolar.

A informática e a internet são fundamentais para a educação, visto que facilitam as pesquisas e apoiam o desenvolvimento de trabalhos pedagógicos inseridos no cotidiano escolar. Em grande parte das escolas, são criados laboratórios de informática com o objetivo de apresentar aos alunos como essas tecnologias podem auxiliá-los em seu cotidiano escolar, contribuindo assim para o desenvolvimento do seu capital intelectual, facilitando a realização de suas atividades (MELO, 2016, p.o7). 
O contexto da informática na educação brasileira se assemelha aos caminhos que o país percorreu para oferecer acesso às tecnologias aos cidadãos, em especial quando da popularização dos computadores e da internet que, inevitavelmente iriam chegar às escolas, sendo preciso adaptações curriculares para a inserção dessas ferramentas.

O primeiro marco legal nesse sentido é a constituição Cidadã de 1988 que assegura aos cidadãos brasileiros direitos sociais invioláveis dispondo em seu artigo $6^{\circ}$, onde discorre que "São direitos sociais a educação, saúde, a alimentação, o trabalho, a moradia, o transporte, o lazer a segurança, a previdência social, a proteção à maternidade e à infância, a assistência aos desamparados, na forma desta Constituição".

A lei de Diretrizes e Bases da Educação assegura em seu artigo 32, inciso segundo que "II- a compreensão do ambiente natural e social, do sistema política, da tecnologia, das artes, e dos valores em que se fundamenta a sociedade”, demonstrando que o contexto tecnológico já era um desafio a ser superado no Brasil iniciando nos anos 90.

Um grande marco legal nesse sentido se deu com os Parâmetros Curriculares Nacionais - PCN, documento lançado em 1988 pelo governo do Brasil tem como principal objetivo a modernização da matriz curricular da educação básica, trazendo como novidade o uso das TICs em educação "a tecnologia deve ser utilizada para gerar situações de aprendizagem com maior qualidade - criar ambientes de aprendizagem em que a problematização, a atividade reflexiva, atitude crítica capacidade decisória e autonomia sejam privilegiadas”(BRASIL, 1998, P.I40).

Outro grande avanço nesse período se deu com a implantação do programa Gov.Br, através da portaria $\mathrm{N}_{122}$, de is de maio de 2003 que determinava a possibilidade de se alocar recurso adicional ao Programa Governo Eletrônico para oferta de internet nas escolas públicas em 2007 o decreto 6.300 de 13 de dezembro, criou o Programa Nacional de Informática na Educação - PROINFO. Posteriormente, o ProInfo também contribuiu para o provimento de banda larga nas escolas públicas, assim como a criação dos Núcleos de Tecnologia Educacional - NTE nas redes estaduais e municipais de ensino, o trabalho do comitê gestor do Programa de Inclusão Digital, contribuiu para a criação de Telecentros apoiados pela comunidade escolar, tais políticas propuseram "melhoria da qualidade do ensino nas escolas, sendo possível garantir aos alunos acesso ao conhecimento através da 
informática, que é uma tecnologia bastante utilizada na sociedade moderna" (MELO, 2or6, p.07).

\subsection{Tecnologias adotadas para mediação pedagógica}

O conhecimento e diferenciação dos formatos de mediação pedagógica que têm em comum a não presencialidade física é importante na defesa de processos educativos qualitativos que cumpram basicamente princípios básicos de acesso ao saber social e historicamente acumulado pela sociedade e a condições reais de exercício da cidadania. Obviamente que se deve considerar que a escola convencional nunca deve ter pensado na possibilidade de seus alunos e professores não poder frequentar as salas de aula. Porém, apenas essa condição, como já foi dito, não insere as práticas pedagógicas no campo da $\mathrm{EaD}$.

É possível entender o porquê do estado do Amazonas, considerando que as soluções são pensadas a partir da realidade que se vive, por exemplo, ter sido um dos primeiros a apresentar uma alternativa pedagógica rápida e, provavelmente, uma das mais abrangentes de todo Brasil.

O Programa Aula em Casa do estado do Amazonas foi uma adaptação de um programa já existente no estado para fazer chegar educação nos lugares de mais difícil acesso do estado para estudantes do $6^{\circ}$ ano do Ensino Fundamental até o $3^{\mathrm{O}}$ ano do Ensino Médio e foi ampliado para os demais estudantes das redes públicas durante a pandemia de COVID-ig.

Em Minas Gerais, o Regime de Estudo Não Presencial conta com diversos suportes técnicos e tecnológicos como o aplicativo Conexão Escola que possui videoaulas, planos de estudo tutorado e recursos didáticos de apoio. Assim como no Mato Grosso, os estudantes podem retirar os materiais impressos na escola caso não tenha internet.

A Secretaria de Educação do Mato Grosso adotou para a rede de ensino do Fundamental I até o Ensino Médio, a plataforma digital Aprendizagem conectada. A plataforma conta com material apostilado, atividades e videoaulas para o Ensino Fundamental. O Ensino Médio, além dos recursos disponíveis na plataforma, conta com aulas transmitidas pela TV Assembleia 5 vezes na semana das $7 \mathrm{~h}$ às $8 \mathrm{~h}$ da manhã. Essas aulas ficam disponíveis no canal do YouTube Pré-Enem Digital. Os estudantes que não 
têm acesso a internet podem retirar os materiais apostilados e atividades nas escolas públicas.

O Rio Grande do Sul adotou a ferramenta Google Classroom como espaço pedagógico. Na plataforma ocorrerão aulas on-line pelo Meets, bem como a utilização de todos os recursos pedagógicos disponíveis na referida plataforma. Dos estados pesquisados, o RS foi o único que previu um período de ambientação para a comunidade escolar, com Jornada Pedagógica e orientações sobre a plataforma e os recursos disponíveis, antes das aulas remotas iniciarem.

Pernambuco adotou um programa coordenado pela secretaria estadual com aulas on-line através do ensino remoto desenvolvido prioritariamente por meio de vídeo aulas e fórum avaliativos. Essas atividades são produzidas na maioria das vezes pela secretaria de educação que produzem conteúdo audiovisual e disponibilizam em plataformas digitais. Percebe-se pela descrição da Secretaria que as atividades partem de um planejamento a partir do uso de uma estrutura de plataforma virtual já existente.

Percebe-se que, mesmo diante das iniciativas dos estados aqui pesquisados, a preocupação é garantir a transmissão de conteúdo no formato equivalente ao que se faz nas salas de aulas presenciais. Reconhece-se, portanto, que os sistemas de ensino, estão desenvolvendo experimentalmente ações pedagógicas adaptadas e, paradoxalmente, a educação precisou acelerar para chegar ao século XXI com questões a serem resolvidas de períodos anteriores.

Em um contexto de cibercultura como a que o mundo vive, as redes sociais digitais, as plataformas de conteúdos estão abarrotadas de informação, de recursos audiovisuais produzidos, de livros digitais e espaços de ensino informal e não formal. A escola precisa apresentar o diferencial nesses processos de ensino que são remotos e emergenciais. Esse diferencial, certamente, é a prática docente que deveria acumular conhecimento específico e didático para apresentar ao estudante em isolamento o que ele efetivamente precisa num cenário de incertezas que uma pandemia carrega.

\subsection{Ensino à distância, ensino híbrido, educação on-line e ensino remoto: limites conceituais}

É relevante diferenciar as terminologias anunciadas nessa seção, demarcando dimensões conceituais que as caracterizam, compreendendo o momento de emergência que 
levou à busca de uma apreensão emergencial, acelerada e por vezes superficial, mas acreditando que as vivências e demandas impostas pelo distanciamento social provocam um aumento no quantitativo e formatos de ensino não presencial,

Presente na Legislação Educacional desde a promulgação da Lei de Diretrizes e Bases (LDB) no 9394/96, já com oferta comum nas instituições de ensino, especialmente de nível superior, a Educação a Distância - EaD adquiriu uma centralidade nas demandas e preocupações da sociedade brasileira a partir do distanciamento social imposto pela Pandemia de COVID-I9.

Emergencialmente as instituições de ensino, os órgãos gestores, os conselhos de regulação, a mídia e a sociedade em geral, passaram a falar de EaD em uma confusão de nomenclaturas que denuncia o desconhecimento e/ou compreensão superficial desta modalidade, utilizando este termo como sinônimo ou similar de muitos outros.

É importante, tendo em vista que a $\mathrm{EaD}$ se caracteriza como uma das modalidades de ensino previstas na LDB e dispõe de ampla regulamentação para o seu desenvolvimento, iniciar sua caracterização, diferenciando em seguida as demais terminologias novas e ainda com regulação e suporte teórico-metodológico incipientes ou em construção.

Contemplada especialmente no artigo 80 da LDB, a EaD tem hoje um Decreto no 9.057/2017, que a define em seu art. Io como. modalidade educacional na qual a mediação didático-pedagógica nos processos de ensino e aprendizagem ocorra com a utilização de meios e tecnologias de informação e comunicação, com pessoal qualificado, com políticas de acesso, com acompanhamento e avaliação compatíveis, entre outros, e desenvolva atividades educativas por estudantes e profissionais da educação que estejam em lugares e tempos diversos. (BRASIL, 2017, p. I)

A dimensão pedagógica já acumula construções sobre formatos de desenvolvimento curricular, material didático multimídia estruturado em modo dialógico, procedimentos avaliativos específicos, demandas de saberes docentes, dimensionamento de conteúdos e práticas a serem trabalhados em formato presencial e ou a distância, ambientes e ferramentas de mediação telemática e sua adequação/pertinência a determinados objetivos de aprendizagem etc. 
O Ensino Híbrido é outro conceito que tem um marco conceitual avançado, com significativa construção teórica desenvolvida recentemente. As pesquisas e estudos sobre a inserção tecnológica em ações formativas vêm apontando para a superação da dicotomia educação presencial e $\mathrm{EaD}$, perspectivando o hibridismo como um caminho que as práticas formativas adotariam gradativamente, a partir da tendência da inserção das Tecnologias da Informação e Comunicação (hoje as Tecnologias Digitais em Rede) nas ações formais de educação.

Sales e Pinheiro (2018, p. 173), defendendo o que chamam convergência entre as modalidades presencial e a distância, enquanto uma decorrência natural da inserção das TIC nos processos formativos destacam como aspecto necessário à implementação de práticas híbridas, o desenvolvimento de uma cultura institucional que agregue naturalmente processos formativos com presencialidade física ou com mediação tecnológica, como processos diversos, mas igualmente promotores do desenvolvimento das habilidades, conteúdos e produções que se almeja.

O hibridismo também já dispõe de um suporte legal relevante, que se origina a partir da autorização para a oferta semipresencial em cursos de graduação desde o ano de 2004 com a Portaria $\mathrm{n}^{\mathrm{o}}$ 4.059/2004. Atualmente, no Brasil, este formato de oferta é regulado pela Portaria MEC n⿳0 1428/2018, que dispõe sobre a oferta, por Instituições de Educação Superior (IES), de disciplinas na modalidade a distância em cursos de graduação presencial. De acordo com esta regulamentação as IES podem ofertar entre $20 \%$ e $40 \%$ da carga horária total dos seus cursos na modalidade a distância, considerando as condições e exigências ali especificadas.

[...] incluir métodos e práticas de ensino-aprendizagem que incorporem o uso integrado de tecnologias de informação e comunicação - TIC para a realização dos objetivos pedagógicos, material didático específico, bem como a mediação de tutores e profissionais da educação com formação na área do curso e qualificados em nível compatível ao previsto no projeto pedagógico do curso - PPC e no plano de ensino da disciplina, que deverão descrever as atividades realizadas a distância, juntamente com a carga horária definida para cada uma, explicitando a forma de integralização da carga horária destinada às atividades on-line. (BRASIL, 2017, p 2.).

Certamente que a abertura dessa possibilidade legal proporcionou às IES experiências e reflexões vivenciais que fomentaram a discussão científica e propiciaram alterações na cultura institucional que hoje constituem a compreensão de Ensino Híbrido no país. Cabe destacar, no entanto, a perspectiva de ensino Híbrido pressupõe a realização 
também de atividades com presencialidade física, o que está impossibilitado pelo contexto pandêmico da COVID-rg que impõe o distanciamento físico.

A educação on-line é um conceito amplo e multifacetado e sem regulamentação no Brasil. Justamente, pelo seu espectro complexo, talvez não caiba colocar o conceito em estruturas rígidas que inviabilizam suas múltiplas potencialidades. Assim, neste estudo, a educação on-line é compreendida como um complexo de ações de ensino-aprendizagem mediadas por tecnologias digitais que fortalecem práticas interativas e hipertextuais (SANTOS, 2019).

Enquanto fenômeno nascido da cibercultura, a Educação On-line, portanto, não é sinônimo de EaD. No entendimento de Santos (2019), a Educação On-line é uma perspectiva pedagógica que pode ser assumida como potencializadora de situações de aprendizagem mediadas por encontros presenciais, a distância ou em processos híbridos.

Deste modo, não são os encontros mediados por tecnologias telemáticas nem a utilização de ambientes virtuais de aprendizagem que caracterizam essa perspectiva educativa, mas sim a cibercultura enquanto fenômeno social associado à maneira como os atores do processo se apropriam das tecnologias digitais e do ciberespaço por meio de processos interativos de autoria e cocriação.

A principal crítica que Santos (2019) sustenta é a de que, muitas vezes, o paradigma educacional dos processos de ensino com mediação tecnológica digital são centrados em pressupostos pedagógicos pautados na transmissão, adotando lógicas massivas das mídias de massa e auto aprendizagem reativa, ao tempo que nas vivências do ciberespaço, no contexto da cibercultura, os sujeitos interagem com as interfaces para produzir e compartilhar coletivamente e em rede, informações e conhecimento.

A educação on-line, nesse sentido, tem princípios e fundamentos engendrados a partir de elementos centrais da cibercultura: o social, a rede e a autoria.

Neste caleidoscópio de conceitos, em razão sobretudo da pandemia de COVID-I9, uma outra terminologia ganha repercussão e visibilidade: o ensino remoto. A legislação vigente, mesmo a construída em razão da pandemia de COVID-ı9, não contempla conceitualmente nem procedimentalmente o ensino remoto como tipologia ou modalidade de ensino. No entanto, o termo se popularizou na mídia, nas redes sociais digitais e entre gestores públicos na tentativa de nomear as ações pedagógicas criadas para atender às 
regulamentações emergenciais emitidas pelos órgãos públicos no que se refere a educação escolar em tempos de pandemia.

As portarias $\mathrm{n}^{\mathrm{o}}$ 544, de $\mathrm{I} 6$ de junho de 2020 e $\mathrm{n}^{\mathrm{o}} 376$, de 3 de abril de 2020 do Ministério da educação dispõem sobre a substituição das aulas presenciais por aulas em meios digitais enquanto durar a situação de pandemia do Novo Coronavírus - COVID-ı9 na educação superior e na educação profissional, respectivamente, em nível nacional. Nesses documentos ficam autorizados, excepcionalmente, a suspensão ou substituição das disciplinas presenciais, em cursos regularmente autorizados, por atividades letivas que utilizem recursos educacionais digitais, tecnologias de informação e comunicação ou outros meios convencionais (BRASIL, 2020b, p.I).

Já as ações voltadas para a educação básica são de responsabilidade dos entes que as gerenciam - estados e municípios - e têm dispositivos legais diversos que, no recorte desta pesquisa, adotam condutas diferenciadas como: regime especial de aulas não presenciais (Amazonas), regime especial não presencial (Bahia), regime de estudo não presencial (Minas Gerais), atividades não presenciais (Mato Grosso), aulas remotas (Rio Grande do Sul). Assim, com exceção do governo do estado no Rio Grande do Sul - que informa adotar aulas remotas como modalidade de ensino por conta da pandemia -, o termo remoto não aparece como tipologia pedagógica nos demais documentos legais.

Embora a legislação não conceitue o ensino remoto nem o adote como categoria fundamentada em referenciais teóricos consolidados, já há discussão em torno do termo que ganhou notoriedade em 2020 .

Santo e Trindade (2020) demarcam o surgimento do ensino remoto emergencial (ERE) a partir de situações atípicas como pandemias e outras catástrofes e o define como possibilidade para a continuidade das atividades pedagógicas com o objetivo de diminuir os prejuízos derivados da suspensão das aulas presenciais. A inclusão dos termos emergencial e do remoto na definição das práticas de ensino desenvolvidas no contexto que o mundo está vivendo em 2020 é fundamental na perspectiva de Tomazinho (2020), pois o que caracteriza o remoto é a impossibilidade de professores e estudantes frequentarem as escolas em razão da tentativa de contenção da propagação do novo coronavírus. Já o emergencial, situa a temporalidade desta alternativa, uma vez que os planejamentos pedagógicos de todas as instituições de ensino foram interrompidos abruptamente, com 
riscos de não mais serem aproveitados no ano de 2020 e novas alternativas precisaram ser adotadas na mesma velocidade.

Desta forma, o ensino remoto é uma alternativa emergencial e pontual adotada, ainda que não nominalmente muitas vezes, por instituições de ensino para tentar que o vínculo pedagógico não seja rompido totalmente. Tem sido desenvolvido no Brasil das mais diversas formas, com a mediação de tecnologias digitais ou não digitais. Nomear referenciadamente as modalidades, tipologias e práticas de ensino é importante para evitar o enfraquecimento e fragilização das áreas educacionais.

\subsection{Experiências pedagógicas na covid-19: convergências e divergências}

Ao que parece não há dúvidas que a pandemia de COVID-ıg implicará em perdas para a educação e para aprendizagem dos mais de 47.00o.ooo de estudantes matriculados no país. Na rede pública, esse hiato é ainda maior, cabendo a cada secretaria de educação propor alternativas para o contexto de suspensão das atividades presenciais físicas, bem como, o planejamento para o retorno dos estudantes.

Essa situação, em um contexto educacional que já enfrenta desafios importantes em função das transformações sociais que o mundo vivencia, ganha novas provocações em razão do cenário pandêmico. Como sinaliza Nóvoa (2020), os sistemas de educação não sabem como lidar com essa crise especificamente e é preciso, reconhecer o não saber, entendendo, porém, que é essencial agir em defesa de uma educação que seja, sobretudo, pautada na luta contra as desigualdades sociais. Assim, interromper as atividades pedagógicas não deveria ser uma opção sob o risco de o estudante não retornar ao espaço escolar.

Esse paradoxo justifica a necessária reação imediata do poder público, o que é um grande dificultador, considerando a heterogeneidade e complexidade das circunstâncias educativas no Brasil que vão desde estudantes em situações sérias de vulnerabilidade social até a formação e profissionalização docente precarizada para desenvolvimento de práticas pedagógicas sem a presença física de alunos e professores no espaço escolar convencional.

O levantamento feito pelo CIEB indicou que apenas quatro estados, ainda no começo da pandemia, deram continuidade ao desenvolvimento de atividades pedagógicas para cumprimento da carga horária letiva. Embora o estudo apresente o levantamento de 
vinte estados, vale afirmar que os demais estados não contemplados e o Distrito Federal também tiveram como primeira ação a suspensão das aulas.

No intuito de compreender os limites, possibilidades, convergências e divergências desse contexto, apresenta-se a seguir, a partir de categorias indicadas - uma análise das ações adotadas por cinco secretarias estaduais de educação do país para lidar com a suspensão das atividades presenciais físicas.

\subsection{Ensino-aprendizagem em casa}

As dimensões territoriais do Brasil e diferenças culturais, econômicas e sociais regionais do país apontam para a dificuldade de implantação de ações pedagógicas uniformes e homogêneas. Não é esse o propósito dos que defendem uma educação significativa, contextualizada e alinhada às realidades locais e regionais, porém, no contexto de pandemia que o país vivencia, esses hiatos e divergências são ainda mais agravados, além de fortalecer as desigualdades e discrepâncias em um país que mantém, por exemplo, o Exame Nacional do Ensino Médio, mesmo que o acesso à educação esteja comprometido para maior parte dos alunos matriculados no Ensino Médio.

\subsubsection{Abrangência do ensino em casa}

O Estado do Amazonas implantou o programa Aula em Casa, por meio do Decreto no 4206I, de I6 de março de 2020 para todos os níveis de ensino, da Educação Infantil até o Ensino Médio. O Governo do Estado de Minas Gerais disponibilizou o programa Estude em Casa a partir de 12 de maio de 2020, abrangendo também os estudantes do Ensino fundamental I ao Médio. O estado do Mato Grosso implantou o programa Aprendizagem Conectada (MATO GROSSO, 2020) a partir de maio para os estudantes do Ensino Fundamental I ao Ensino Médio.

Já o estado do Rio Grande do Sul (2020) iniciou um programa de Aulas Remotas em i de junho para os estudantes do Ensino fundamental I ao Médio, sendo que a primeira etapa foi destinada a ambiência nos ambientes virtuais para professores e estudantes e as atividades remotas iniciaram em 29 de junho.

Entre os estados aqui analisados, a Bahia foi o único que após a suspensão das atividades presenciais não apresentou programa e/ou projeto específico para continuidade 
das atividades pedagógicas remotas de forma ordenada em toda a rede. Em maio de 2020, a Secretaria de Educação da Bahia, junto com a Undime Bahia, a União de Prefeitos da Bahia (UPB) e a União de Conselhos Municipais de Educação (UNCME) divulgou um documento denominado Orientações Gerais para os Sistemas e Redes de Ensino da Bahia que apresenta orientações relacionadas ao planejamento, à execução e ao acompanhamento de ações, visando minimizar o impacto da interrupção das atividades letivas para os estudantes e, ao mesmo tempo, manter os vínculos da comunidade escolar e a Plataforma da Rede de Práticas.

O documento reúne as iniciativas pedagógicas criadas pelos municípios da Bahia em todos os níveis de ensino. O governador declarou, inclusive, que o Estado não tem condições de padronizar aulas pela internet na rede estadual, a maioria dos alunos é de baixa renda e de menor poder aquisitivo. Não dá para substituir aula presencial por aula pela internet (BAHIA, 2020).

Deste modo, considerando que o estado da Bahia possui 417 municípios, ficou inviável neste artigo reunir as práticas isoladas. Além disso, a intenção é destacar as proposições sistematizadas e coordenadas pelas secretarias estaduais que, por conta da sua

abrangência e alcance, possuem os maiores quantitativos de estudantes e docentes. Ainda assim, o documento supracitado reúne estratégias das redes municipais para o Ensino Fundamental e Médio e destaca que no caso da Educação Infantil, as atividades serão compensadas, a posteriori, de forma presencial, considerando os limites impostos pela legislação.

\section{METODOLOGIA}

Trata-se de uma pesquisa em que foi utilizado o método de revisão bibliográfica, que é desenvolvida com base em um material formado, geralmente, por livros, sites oficiais, publicações periódicas e artigos científicos. As principais publicações periódicas são jornais e revistas. Essas, juntamente, com os artigos científicos, possibilitam uma cobertura de conteúdo mais ampla e diversificada em comparação a pesquisa direta, sendo assim, há vantagem nesse método para um maior agrupamento de informação sobre o tema escolhido. 
Dessa forma, tem-se a estrutura bibliográfica em total relevância para o conhecimento e aprendizagem de novas informações, haja vista que, por muitas vezes, é um dos principais meios de estudo para o pesquisador. Sabendo disso, a pesquisa bibliográfica é um impulsionamento na área de coleta de dados e conceitos já testados, possibilitando a aquisição de novos conhecimentos e construção da autonomia crítica e metodologia sobre o que foi apresentado no estudo (GIL, 2002).

A presente pesquisa se utilizou de diversas literaturas encontradas nos recursos da revisão bibliográfica, em que procurou-se compreender sobre a inclusão digital em escolas públicas, os benefícios e dificuldades encontradas nessa inclusão, além de evidenciar como a tecnologia pode influenciar numa melhor qualidade de vida.

Os artigos utilizados para o embasamento dessa pesquisa foram encontrados na base de dados Scielo, considerou-se artigos científicos de livre acesso, em língua portuguesa, nos últimos io anos. A pesquisa teve duração de, aproximadamente, dois meses e meio, correspondendo as datas de or de Setembro e is de Dezembro de 2020.. Para o processo de pesquisa, foram utilizadas palavras chaves como: Inclusão digital, tecnologias e escolas públicas.

\section{RESULTADOS E DISCUSSÃO 4.I A importância do acesso à informação e inclusão digital em escolas públicas}

A Revolução da Informação envolve eletrônicos e questões digitais permitindo que o indivíduo esteja mais integrado com a comunidade eletrônica, coloca-o em contato com pessoas que estão distantes fisicamente, colabora com a troca de informações e aprendizagem continuada. Concernente aos alunos de escolas públicas, além das promoções citadas, promove-se a cidadania digital permitindo a integração, efetividade e interação no mundo por meio da inclusão digital. Diante disso, a Lei federal n. 12.527/20II, também conhecida como Lei de Acesso à Informação - LAI, com que o povo brasileiro passou a contar com um importante facilitador da participação do cidadão na esfera governamental, determina que o acesso às informações estatais seja regra, o que colabora para o desenvolvimento e consolidação da atuação do cidadão.

A Constituição Federal garante que se tenha informações abertas com conteúdo de interesse coletivo ou particular, partindo desde questões políticas a consulta de disponibilidade de vagas em escolas públicas. O direito a informação é um dos direitos 
humanos fundamentais, entretanto, a população não consegue ter acesso a esses meios, muitas vezes, devido a falta de instrução no manuseio das TICs (BRASIL, 1988). Dessa forma, é imprescindível o domínio de ferramentas que estejam relacionadas como o acesso e manipulação de informação, haja vista que a sociedade está cada vez mais informatizada, atualmente, grande parte dos recursos e veículos de informação são eletrônicos e digitais. Entre muitos recursos que compõem as TICs, a internet está sendo a mais utilizada e a mais popular.

Devido suas variadas potencialidades, como a velocidade e praticidade, muitos meios de comunicação foram substituídos, além da maioria dos meios de informação sobre mundo, a própria sociedade, mudanças que afetam a população ou notícias, estão disponíveis por meio de tecnologia (BARROS, 2015).

\section{CONSIDERAÇÕES FINAIS}

Percebe-se que, com a tecnologia tem se incluído as atividades cotidianas de toda população, desde a comunicação até meios de informação política. A análise de dados e conteúdos sobre inclusão digital em escolas públicas permitiu uma melhor compreensão acerca das necessidades e dificuldades encontradas no processo de aprendizagem de novas informações relacionadas à tecnologia, principalmente, pelo medo de danificar os aparelhos e a falta de prática nas atividades concernentes as TICs.

Entretanto, é importante e essencial deixar em evidência a mudança na qualidade de vida que a tecnologia pode proporcionar à sociedade, possibilitando um exercício cognitivo, como em relação a memória e atenção, além de facilitar a socialização entre os idosos e seus grupos de familiares e amigos. Porém, a análise de dados e conteúdos sobre inclusão digital permitiu uma melhor compreensão acerca das necessidades e dificuldades encontradas no processo de aprendizagem de novas informações relacionadas à tecnologia de acordo com suas necessidades e potencialidades, assim, o acesso para as novas tecnologias estará no alcance de todos públicos. Além disso, a importância de entender os limites que cada pessoa vivencia para ser ter um ensino individual e especializado facilitando a usabilidade nos dispositivos tecnológicos. 


\section{REFERÊNCIAS}

AMAZONAS, Governo do Estado do. Secretaria de Educação e Desporto. Decreto no 4206I, de i6 de março de 2020. Aula em casa, 2020. Disponível em: http://aulaemcasa.am.gov.br/. Acesso em: 5 jun. 2020.

ANJOS, Rosana; SILVA, Lídia; ANJOS, Alexandre. Ensino híbrido: organização e sistematização de conceitos com base em revisão sistemática da literatura. Revista Em Rede, $\quad$ v. $\quad 6, \quad$ n. $\quad 2, \quad$ 2019. Disponível em: https:// www.aunirede.org.br/revista/index.php/emrede/issue/view/r4. Acesso em: ro jun. 2020.

ARAUJO, S.P. de; VIEIRA, V.D; KLEM, S.C. dos S.; KRESCIGLOVA, S.B. Tecnologia na Educação; Contexto histórico, papel e diversidade. IV Jornada de Didática III Seminário de Pesquisa do CEMAD. 2017. Disponível em: http://www.uel.br/eventos/jornadadidatica/pages/arquivos/IV\%20Jornada\%20de\%20Di adatica\%20Docencia\%20na\%20 Contemporaneidade\%20e\%\%20III\%20Seminario\%20de\%20 Pesquisa\%2odo\%\%20CEMAD/TECNOLOGIA\%20NA\%2oEDUCACAO\%20CONTEX TO\%2oHISTORICO\%2oPAPEL\%2oE\%2oDIVERSIDADE.pdf. Acesso em ro novembro de 2020 .

ARRETCHE, M. A Geografia Digital no Brasil: Um panorama das desigualdades regionais. In: Desigualdades Digitais no Espaço Urbano: Um estudo sobre o acesso e o uso da internet na cidade de São Paulo. Comitê Gestor da internet no Brasil. 2019. Disponível em https://cetic.br/media/docs/publicacoes/7/I1454920191028desigualdades_digitais_no_espaco_urbano.pdf. acesso em I4 de novembro de 2020 .

BASTOS, R.C.; BIAGIOTTI, B. MOOCs: uma alternativa para a democratização do ensino. Renote. V. I2, n.I, 2014. DOI: https://doi.org/10.22456/1679-1916.50333

BARROS, B.M.C. de,; GOULART, G. M. O Acesso à Internet no Brasil e a inclusão digital: Uma análise dos avanços e retrocessos do programa nacional de banda largaPNBL.2or6. Disponível em: http://online.unisc.br/acadnet/anais/index.php/snpp/article/view/r457I/3354. Acesso em I6 de novembro de 2020 .

BAHIA, PORTARIA UNCME no ooI/2020. Estado da Bahia, i3 de março de 2020.Estabelece orientações gerais e critériospara ações das Coordenações Estaduais,VicePresidências e Diretorias da UNCMEcom referência ao acompanhamento docombate ao COVID I9 (novo coronavirus). . Disponível em: https://www.uncme.org.br/Gerenciador/arquivos/fa77c6424823d993e61889db5e7bae62 .pdf. Acesso em: 27 abr. 2020 .

BAHIA, Governo do Estado da. Rui Costa suspende aulas por mais is dias na Bahia. 28 abr. 2020. Disponível em: http://escolas.educacao.ba.gov.br/noticias/rui-costa-suspendeaulas-por-mais-15- dias-na-bahia. Acesso em: 18 maio 2020. 
BRASIL. Ministério da Educação. Portaria no 544/2020. Dispõe sobre a substituição das aulas presenciais por aulas em meios digitais, enquanto durar a situação de pandemia do novo coronavírus - Covid-19, e revoga as Portarias MEC no 343 , de 17 de março de 2020, no 345 , de 19 de março de 2020, e no 473 , de 12 de maio de 2020. Diário Oficial da União, Brasília, i6 jun. 202ob.

BRASIL. PARECER № 5/2020 DO CNE, Orienta a reorganização do Calendário Escolar e dá possibilidade de cômputo de atividades não presenciais para fins de cumprimento da carga horária mínima anual, em razão da Pandemia da COVID-19. Disponível em: http://portal.mec.gov.br/index.php?option=com_docman\&view=download\&alias=I45 oII-pcpoo5-20\&category_slug=marco-2020-pdf\&Itemid=30192. Acesso em: 25 abr. de 2020 .

BRASIL. A Base - Brasília: MEC. 2018 a. Disponível em http://basenacionalcomum.mec.gov.br/a-base. Acesso em i7 de novembro de 2020.

BONILA, M. H. S.; PRETTO, N de L. Inclusão Digital: Polêmica Contemporânea. [online]. Salvador: EDUFBA, r88p, 2orr. Disponível em http://books.scielo.org Acesso em 20 de outubro de 2020 .

CERQUiNHO, K. G; TAVARES, W; PAULA, A.P P de; VITORINO, I. A. Inclusão Digital para quê e para quem? Observação do Portal Inclusão digital do Governo Federal Brasileiro. Cadernos Gestão Pública e Cidadania. São Paulo, v.2o, n.67, Jul/Dez.2015. DOI: http//dx.doi.org/10.1266o/cgpc.v2on67.32927

COSTA, L. F. Novas tecnologias e inclusão digital: Criação de um modelo de análise: IN: BONILlA, M. H. S; PRETTO, N. de L. Inclusão Digital: Polêmica contemporânea. [online]. Salvador: EDUFBA, I88p, 20II. Disponível em http://books.scielo.org. Acesso em ro de Novembro de 2020.

DIAS, L.R. Inclusão digital como fator de inclusão social. In: BONILLA, M.H.S; PRETTO, n. de L. Salvador: EDUFBA, I88p, 20Ir. Disponível em http://books.scielo.org. Acesso em ro de Novembro de 2020.

GIL, A, C. (2002). Como Elaborar projeto de pesquisa. $4^{\underline{a}}$ ed. São Paulo: atlas S/A.

MELO, A.F. A Inclusão Digital na Escola Para a Erradicação do Analfabetismo Tecnológico. E-Mosaicos. V.5, n. Io (2016). Disponível em:http://www.epublicacoes.uerj.br/index.php/e-mosaicos/article/view/26618/18985. Acesso em 7 de Novembro de 2020.

NÓVOA, António. Palestra proferida na abertura da Formação Continuada Territorial a Distância, Salvador (Bahia), abr. 2020. Disponível em: https://www.youtube.com/watch?v=wx-deAxdegE. Acesso em: 03 de maio de 2020.

PRIOSTE, C.; RAIÇA, D. Inclusão digital e os principais desafios educacionais brasileiros. Revista on line de Política e Gestão Educacional. V. 21, N. esp. I, out/2017. 
DOI: http://doi.org/I0.22633/rpge.v21.n.espi.out.2017.10457. Acesso em I7 de Novembro de 2020.

RIBEIRO, C. C. de S. O uso de tecnologias digitais nos anos iniciais do ensino fundamental. Trabalho de Conclusão de Curso. UFSJ.2019. Disponível em:http://dspace.nead.ufsj.edu.b/trabalhospublicos/bitstream/handle/r23456789/331/TC C\%20CORRIGIDO\%20FINAL\%20-\%20CL\%c3\%8IUDIA.pdf? sequence $=\mathrm{I} \&$ is Allowed $=\mathrm{y}$. Acessso em o9 de Novembro de 2020.

SANTOS; Edméa. Pesquisa-formação na cibercultura Teresina: EDUFPI, 2019.

SANTO, Eniel E.; TRINDADE, Sara Dias. Educação a distância e educação remota emergencial: convergências e divergências. In: MACHADO, Dinamara P. Educação em tempos de COVID-ı́: reflexões e narrativas de pais e professores. Curitiba: Editora Dialética e Realidade, 2020.

SCARANTI, D.R. Inclusão Digital: Comunicação e Educação para o desenvolvimento. ReabTic, $\quad$ v.I, n.7, 2017. Disponível em:http://revistas.setrem.com.br/index.php/reabtic/article/view/24I/II4. Acesso em I5 de novembro de 2020 .

SIEMENS, G. Connectivism: A Learning Theory for the Digital Age. 2004. Disponível em< http://usuarios.upf.br/ teixeira/livros/conectivismo[siemens].pdf $>$. Acesso em I7 de novembro de 2020 .

SILVA, M. A. R. da Inclusão Digital nas Escolas Pública: $O$ uso Pedagógico do PROINFO Natal/RN. EDUFRN. 2018. Disponível em:http://repositorio.ufrn.br/jspui/bitstream/r23456789/2589o/IInclus\%c3a3\%2odigital\%2 onas\%2oescolas\%2op\%c3\%bablicas.pdf. Acesso em i8 de novembro de 2020.

SILVEIRA, S.A. A noção da exclusão digital diante das exigências de uma cibercidadania. 2008. In: DIAS, L.R. Inclusão digital como fator de inclusão social. In: BONILLA, M. H. S; PRETTO, N. de L. Inclusão Digital: Polêmica Contemporânea[online]. Salvador: EDUFBA, I88p, 20Ir. Disponível emhttp://books.scielo.org. Acesso em io de Novembro de 2020 .

TOMAZINHO, P. Ensino Remoto Emergencial: a oportunidade da escola criar, experimentar, inovar e se reinventar. Medium, 5 abril 2020. Disponível em: https://medium.com/@paulotomazinho/ ensino-remoto-emergencial-a-oportunidade-daescola-criar-experimentar-inovar-e-se-reinventar6667bas5dacc. Acesso em: 20 maio 2020.

XABREGAS, Q. F; BRASILEIRO, T.S.A. Política de Inclusão Digital: Possibilidades para ensinar, aprender e incluir na Amazônia Paraense. Educazônia, Ano I2, vol XXIII, n.2, jul-dez 2019. Disponível em: http://peridodicos,ufam.edu.br/index.php/educamazonia/article/view/6778/4773. Acesso em ro de Novembro de 2020. 